\title{
Cristais de hemoglobina em sangue de capivaras (Hydrochaeris hidrochaeris) e sua importância pericial
}

\section{Crystal of hemoglobin in capybaras (Hydrochaeris hidrochaeris) blood and its skillful importance}

\author{
Luiz FRANCESQUINI JÚNIOR¹, Monica Aparecida FRANCESQUINI², Gláucia Maria Bovi AMBROSANO³, \\ Célia Marisa Rizzatti BARBOSA ${ }^{4}$, José Eduardo CORRENTE ${ }^{5}$, Eduardo DARUGE ${ }^{6}$, \\ Saturnino Aparecido RAMALHO ${ }^{7}$, José Carlos de Freitas Garcia CALDAS ${ }^{8}$
}

FRANCESQUINI Jr, L.; FRANCESQUINI, M.A.; AMBROSANO, G.M.B.; BARBOSA, C.M.R.; CORRENTE, J.E.; DARUGE, E.; SATURNINO, A.R.; CALDAS, J.C.F.G. Cristais de hemoglobina em sangue de capivaras (Hydrochaeris hidrochaeris) e sua importância pericial. Saúde, Ética \& Justiça, 5/7(1-2):17-23, 2000-2002.

\begin{abstract}
Resumo: O presente trabalho teve como objetivo selecionar um método para identificação de animais, fornecendo subsídios indispensáveis para a caracterização ou descaracterização de crime, tanto na matança de animais silvestres como torturas de animais domésticos, ambos protegidos por lei, bem como verificar a cristalização da hemoglobina, mais precisamente da oxihemoglobina, em sangue "in natura", com anticoagulante e coagulado de capivaras. Foram utilizadas preparações modificadas de Costa (1929) que possui baixo custo de implantação, rapidez na obtenção dos resultados, por ser de fácil preparação e manejo. Após a compilação e análise dos dados verificou-se que a quantidade, o tamanho, a cor, o local e o contorno do cristal não estão associados ao sexo do animal e que a quantidade de cristal depende da técnica empregada, sendo a técnica 2 (o sangue fresco oxalatado é centrifugado, o sedimento é laqueado pela saponina; adiciona-se sulfato de sódio, agita-se energicamente e em seguida centrifuga-se durante 10 minutos na velocidade 4) a que produz mais cristais, maiores, com coloração mais intensa (rosa intenso) e com distribuição regular na lâmina.
\end{abstract}

Unitermos: Roedores. Hemoglobinas. Antropologia forense. Cristalografia/métodos. Sistemas de identificação animal/ métodos.

\footnotetext{
1. Doutor em Odontologia Legal e Deontologia e Aluno de Doutorado do Curso de Clínica Integrada da FOP/UNICAMP. e-mail: Fran@fop.unicamp.br

2. Mestranda do Curso de Odontologia Legal e Deontologia da FOP/UNICAMP.

3. Professora Adjunta em Bioestatística do Depto. de Odonto-Social - FOP/UNICAMP. e-mail: gláucia@fop.unicamp.br

4. Profa. Associada do Depto. de Prótese e Periodontia da FOP/UNICAMP.

5. Depto. de Ciências Exatas - ESALQ/USP.

6. Prof. Titular em Odontologia Legal e Deontoloiga da FOP/UNICAMP.

7. Doutor em Odontologia Legal e Deontologia pela FOP/UNICAMP.

8. Mestre em Odontologia Legal e Deontologia.

Endereço para correspondência: Rua São José, 996, apto. 73 Edifício Rita Holland, CEP 13400-330, Centro, Piracicaba, SP.
} 
FRANCESQUINI Jr, L. et al. Cristais de hemoglobina em sangue de capivaras (Hydrochaeris hidrochaeris).

\section{Introdução}

$\mathrm{O}$ estudo do sangue é realizado pela hematologia forense, sendo de grande importância para o Direito Penal e Civil, sendo este constituído de uma parte líquida e uma parte sólida. Nesta última, encontram-se os elementos figurados. Sabe-se que, em dado volume de sangue, há aproximadamente 40 a $45 \%$ de hemácias.

Nas capivaras verifica-se para os machos 4.670.000 hemácias e para as fêmeas 4.800 .700 (Jiménez, 1995). Esta tem grande destaque devido a presença de hemoglobina em seu protoplasma ${ }^{8,10}$.

A molécula da hemoglobina dos mamíferos é um tetrâmero cujas dimensões são 64×55x50 Angstron, formada por quatro subunidades, contendo um grupo heme ligado a um polipeptídeo. Deve-se ao heme a propriedade que a hemoglobina tem de se combinar com moléculas de oxigênio, possibilitandoIhes transportá-lo ou armazená-lo.

Cada molécula de hemoglobina pode carregar quatro moléculas de oxigênio, apenas por causa da avidez do oxigênio pelo ferro contido na hemoglobina. Esta avidez química, depende muito da pressão, ou seja quando o oxigênio é empurrado com força contra a hemoglobina, a combinação ocorre em número muito maior de moléculas.

A molécula de hemoglobina por conter ferro pode ser facilmente cristalizável e esta se cristaliza em sistemas diferentes, conforme o sangue de sua proveniência (venosa ou arterial) e conforme a técnica empregada ${ }^{18}$.

Quando se depara com uma mancha de sangue, utiliza-se a diagnose sanguínea específica, para a verificação desta mancha. Para este fim, utiliza-se as "provas de certeza", estas fornecem, ao perito, elementos de grande valia para o êxito das investigações ${ }^{1,9,11}$.

Dentre as provas de certeza, há a reação cristalográfica. Esta nos fornece sistemas diferentes de cristalização, permitindo com isso a identificação da espécie de onde proveio tal sangue $e^{7,14,6}$.
A cristalização da hemoglobina permite a diagnose específica do sangue ${ }^{7}$.

É indispensável o estudo das qualidades ópticas dos cristais, as suas características cristalográficas e o seu arranjo nas preparações, com o objetivo de individualizar a amostra o mais preciso possível ${ }^{13,14}$.

Inúmeras pesquisas e trabalhos já foram elaborados sobre esta importante "prova de certeza", demonstrando a grande valia desta para a solução de crimes hediondos e furtos, entre outros, tendo em vista que, em muitos crimes, as manchas de sangue estão presentes ${ }^{2,3}$.

Por se tratar de um trabalho minucioso, muito ainda há por se fazer, para se viabilizar a sua utilização em todo o território nacional.

O presente trabalho objetivou selecionar um método para identificação de animais cujos resultados sejam rápidos, seguros, de baixo custo e de fácil manejo associado ao fato de dispensar pessoal, drogas, máquinas e equipamentos sofisticados e de custo elevado.

Atualmente pode-se contar com duas outras provas de certeza para a identificação do sangue de animais, trata-se do teste de soro-precipitação ou "UHLENHUTH" e do teste de "DNA". Ambos produzem resultados seguros, mas ambos demandam pessoal especializado, maquinário e equipamentos de custo relativamente alto e são métodos cujos resultados não são obtidos de imediato. Por outro lado, embora a técnica de 'UHLENHUTH' (soro precipitação) seja bastante utilizada, no campo Médico-Forense, existem muitas dificuldades na praticidade da aplicação desta técnica, uma vez que os laboratórios periciais necessitam de soros específicos de determinados animais com titulação elevada para testarem as amostras que se pretendem ampliar identificando a que tipo de animal pertencem a mesma. Além disso, embora o "DNA" represente a impressão digital genética de uma determinada pessoa ou de um determinado animal, a de se ressaltar que a individualidade de suas características nos permitem apenas estabelecer uma análise comparativa com 
padrões pré-existentes. No Brasil não existe ainda um padrão de "DNA" para a espécie estudada. Devido a estes fatos, estes testes tornam-se inviáveis e em muitos casos impraticáveis.

Levando-se em conta também as desigualdades existentes entre as várias regiões, principalmente a desigualdade econômica de muitas delas, esta impraticabilidade torna-se mais acentuada, chegando ao ponto de muitos afirmarem serem impossíveis as identificações de animais pelo sangue. Este fator é de grande relevância pois estes testes são partes integrantes e muitas vezes são fatores incriminatórios, sem os quais os delitos ou barbáries praticados, deixam de existir por falta de provas, ficando o Juiz ou autoridade competente impossibilitado de cumprir a Lei.

O teste para obtenção de cristais de hemoglobina se justifica, pelo fato de nele serem empregados apenas quatro drogas, de fácil obtenção, fácil manipulação e baixo custo, além de um microscópio óptico simples, uma centrífuga e algumas lâminas.

Uma vez obtida a lâmina do sangue encontrado no local do crime, pode-se através do padrão óptico do arranjo estrutural dos cristais de hemoglobina, que segundo vários autores ${ }^{2,3,7,16}$ são específicos para cada espécie animal, estabelecer-se por comparação de qual animal proveio tal sangue caracterizando ou descaracterizando um possível crime.

Desta forma, os profissionais da área da saúde, ao receberem, ou ao serem chamados para o local do crime, a fim de remover sangue para exame, quer "in natura", em manchas ou sob a forma de crostas, suspeito de pertencerem a um determinado animal silvestre, bem como, a um animal doméstico submetido a morte ou tortura, poderá satisfazer as autoridades competentes, ao utilizar este teste, fornecendo subsídios indispensáveis para a caracterização ou descaracterização do crime. Tanto os animais domésticos (nos casos de torturas), como os silvestres (nos casos de matança) são protegidos pela Lei, através do artigo 225 inciso VII e parágrafo 3ํ da Constituição da República Federativa do
Brasil ${ }^{4}$, sendo também garantida esta proteção pelos artigos $193 \mathrm{em}$ seu inciso $X$ e artigo $195 \mathrm{da}$ Constituição do Estado de São Paulo17, e pela Lei de proteção à fauna ํㅜ 5197 de 03 de janeiro de 1967 em seus artigos $1^{\circ}$, $3^{\circ}, 10^{\circ}, 27^{\circ}$, no caput e parágrafos $1^{\circ}, 5^{\circ}$, deste mesmo artigo, além dos artigos 31 e $34^{5}$. Estes últimos, estabelecem, como penalidade, dependendo da forma como foi praticado o ato (caça, transportes, etc.), reclusão de 1 a 3 anos e de 2 a 5 anos, independentemente de queixa; por serem estes crimes caracterizados como inafiançáveis e são referendados pela Lei no 9.605 de 13 de fevereiro de $1998^{4}$. A verificação das espécies através dos cristais de hemoglobina, pelo fato de ser esta de fácil manipulação, baixo custo, de resultados de rápida obtenção poderá viabilizar a aplicação da Lei na sua integralidade e aumentar a esperança na perpetuação e aumento dos animais ameaçados de extinção e que são caçados indiscriminadamente pela sua pele, pena ou carne.

Segundo os autores, que se dedicaram ao estudo da cristalografia, esta é a mais delicada prova das diferenças de constituição química, pois se acompanha da diferença de estrutura física ${ }^{7,13,14}$.

O presente trabalho pretende verificar a cristalização da hemoglobina do sangue de capivara, utilizando-se as preparações propostas por $\mathrm{Costa}^{7}$ e preparações com modificações desenvolvidas nessa pesquisa, apontando dentre estas qual ou quais as melhores técnicas, para identificação da espécie animal estudada, fornecendo subsídios indispensáveis para a caracterização ou descaracterização de crime.

\section{Material e métodos}

Para a análise dos cristais de hemoglobina, primeiramente padronizou-se a forma associada da hemoglobina a ser estudada como sendo a oxihemoglobina, por ser a mais estável. Esta análise foi efetuada em sangue de capivaras provenientes do setor de Zootecnia da ESALQ/USP. 
FRANCESQUINI Jr, L. et al. Cristais de hemoglobina em sangue de capivaras (Hydrochaeris hidrochaeris).

Para verificar a formação ou não dos cristais de hemoglobina, utilizou-se as três preparações propostas e idealizadas por $\mathrm{Costa}^{7}$ e as modificadas neste trabalho.

Na primeira, o sangue fresco foi tratado com oxalato de amônio triturado, na proporção mínima de $5 \%$; juntou-se saponina e agitou-se o sangue com bastão de vidro. As preparações foram feitas e conservadas à temperatura ambiente.

$\mathrm{Na}$ segunda, o sangue fresco oxalatado foi centrifugado, o sedimento foi laqueado pela saponina; juntou-se sulfato de sódio, agitou-se energicamente e em seguida centrifugou-se (10 minutos velocidade 4), fazendo-se as preparações que foram conservadas em temperatura baixa.

$\mathrm{Na}$ terceira preparação, ao coágulo junta-se saponina e oxalato. Tritura-se, cuidadosamente num gral, durante o tempo necessário à transformação do coágulo em líquido, o qual deve ser tratado por sulfato de sódio e em seguida centrifugado durante dez minutos na velocidade 4 da Centrífuga Excelsa Baby 1, modelo 206 Fanem. As preparações foram conservadas em temperatura baixa.

Na Quarta preparação o sangue oxalatado foi preparado como na Segunda técnica, substituindose apenas a droga ao invés de saponina, utilizou-se $o$ éter.

Uma vez estabelecidos as formas de preparações a serem utilizadas, tornou-se necessário estabelecer qual animal seria pesquisado. O critério para esta seleção foi o de se estudar animais silvestres que podem ser utilizados como alimentação, e/ou animais cuja, pele, etc., possuam algum valor comercial, sempre levando em consideração a disponibilidade de tais animais, bem como o seu perfeito manejo, pois não se justificaria o sacrifício de um animal silvestre, para se obter somente alguns milímetros de sangue, não estando desta forma, lutando por sua preservação. Todos os procedimentos de coleta do sangue destes animais foram realizados pelos Técnicos ou Veterinários responsáveis pelos mesmos, lotados no Setor de Zootecnia da ESALQ/USP.
Com vista nestes critérios elegeu-se a capivara (macho e fêmea) como o animal a ser analisado, sendo analisado 18 lâminas de sangue de machos e fêmeas, sendo utilizado as três preparações propostas por Costa ${ }^{7}$ sendo uma amostra lutada com luto de Look e a outra não, num total de 36 (trinta e seis) amostras.

Uma vez obtida as lâminas, estas foram observada nos intervalos de doze, vinte e quatro, quarenta e oito horas, utilizando-se de fichas de coleta confeccionadas para tal objetivo. Esta observação foi necessária para se verificar o tempo para a formação (cor, definição de contorno, tamanho, quantidade, localização) e completa dissolução ou desintegração do cristal. Neste intervalo de tempo, quando houve cristalização esta foi devidamente registrada por fotomicrografias obtidas da observação de um determinado quadrante da lâmina. Inicialmente em um pequeno aumento $(6,3)$, para se observar o padrão de distribuição dos cristais na lâmina, numa segunda tomada utilizou-se aumentos maiores (10, 16, $40 \mathrm{e}$ $100)$, com ou sem imersão, objetivando visualizar o arranjo cristalográfico assumido pelo cristal, uma terceira tomada em imersão com aumento de $40 \mathrm{e}$ 100 objetivando observar a forma assumida nas terminações de cada cristal isoladamente.

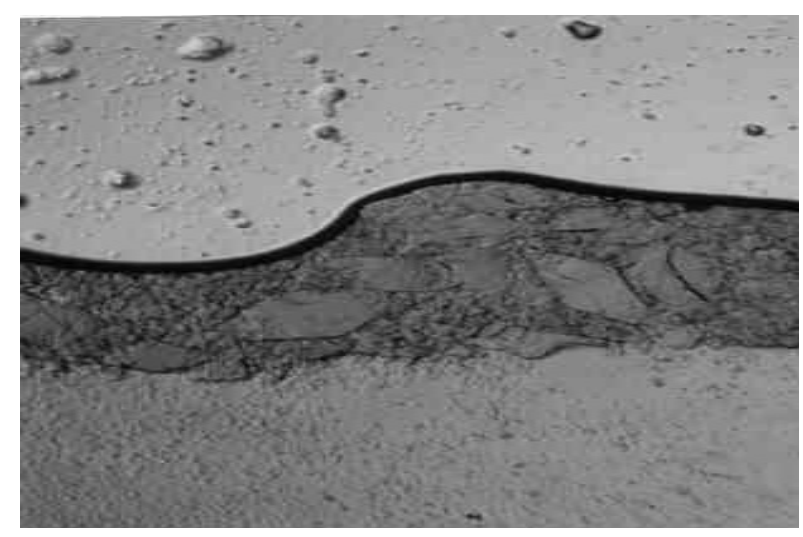

Figura 1 - Cristais obtidos do sangue de capivara, utilizando-se a técnica 2, com luto, aumento 6.3, optovar 1.6, duplo filtro azul, sem imersão.

Uma vez finalizado os trabalhos verificou-se por microfotografias se houve um padrão de distribuição 
ou de formação estrutural constante. Destas cristalizações, devidamente registradas em microfotografias, foram obtidos esboços do cristal.

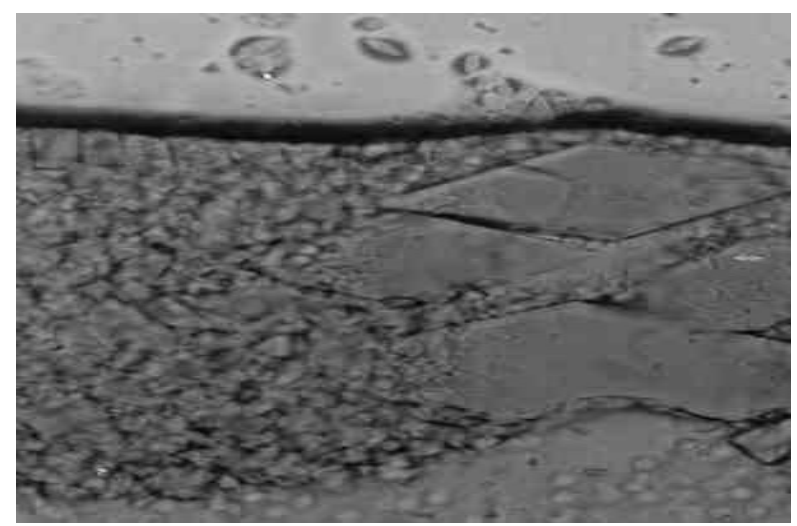

Figura 2 - Cristais obtidos do sangue de capivara, utilizando-se a técnica 2, com luto, aumento 16, optovar 1.6, duplo filtro azul, com imersão.

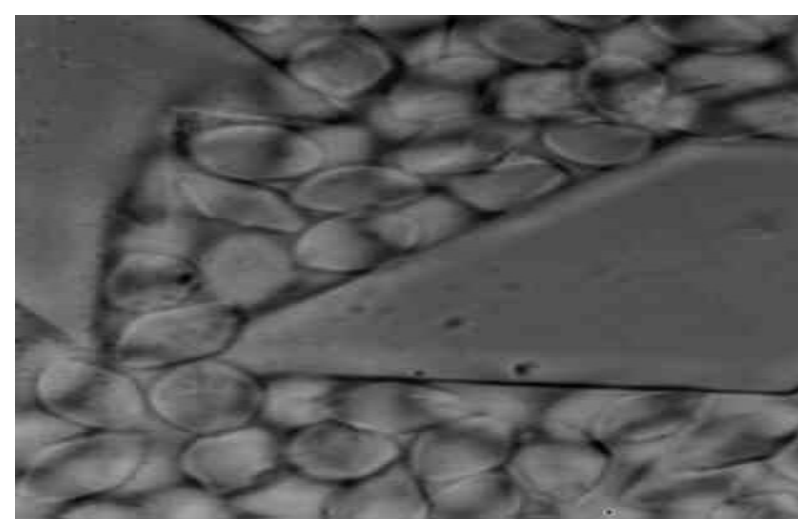

Figura 3 - Cristais obtidos do sangue de capivara, utilizando-se a técnica 2, sem luto, aumento 100, optovar 1.25, filtro azul, com imersão.

Para realizar microfotografia é necessário uma máquina fotográfica com regulagem de exposição automática e um tubo adaptador para ligá-lo ao microscópio que amplie a imagem entre 40 a 150 vezes. O conceito de microfotografia só pode ser aplicado quando se registram imagens que foram ampliadas no mínimo, 40 vezes. Quanto maior a ampliação, maior a necessidade de luz para distinguir cores e formas.

A análise dos resultados foi realizada com 0 intuito de se averiguar qual das três técnicas empregadas nos exames fornece um resultado cristalográfico (cor, tamanho, localização, definição de contorno) mais indicado para cada uma das condições do sangue examinado, observou-se, também, em quais casos o resultado é mais seguro (formou ou não cristais).

Tendo em vista os resultados obtidos do sangue dos animais, verificou-se se o padrão cristalográfico permanecia constante, bem como estabeleceu-se o tempo necessário para obtenção dos mesmos, e verificou-se se havia diferenças cristalográficas quanto ao sexo.

\section{Resultados e discussão}

Após a realização da coleta do sangue, manipulação e obtenção das lâminas, os resultados foram submetidos a análise estatística pelo teste Exato de Fisher $(\alpha=0,05)$, e as fotografias são listadas no apêndice.

Observou-se pelo teste exato de Fisher que a quantidade, o tamanho a cor, o local e o contorno do cristal não estão associados ao sexo do animal $(P>0,05)$. Mas a quantidade de cristal depende da técnica empregada. Assim, nas primeiras 12 horas, na técnica 1 , em $58 \%$ dos casos haviam muitos cristais e em $42 \%$ dos casos haviam poucos, na técnica 2 haviam muitos cristais em todas as repetições, já na técnica 3, não havia nenhum cristal. $\mathrm{Na}$ técnica 4 , em $92 \%$ dos casos haviam poucos cristais e em $8 \%$ não haviam cristais.

Com 24 e 48 horas, haviam muitos cristais em todas as repetições das técnicas 1 e 2 , poucos cristais em todas as repetições da técnica $4 \mathrm{e}$ nenhum cristal na técnica 3 .

A técnica utilizada influenciou no tamanho do cristal $(P<0,05)$, tanto as 12 horas, como as $24 \mathrm{e}$ 48 horas, $100 \%$ dos cristais da técnica 1 tinham tamanho médio, $100 \%$ dos cristais da técnica 2 tinham tamanho grande. Na técnica 4, 91\% tinham tamanho pequeno e $9 \%$ tamanho médio.

A técnica influenciou, também a cor do cristal $(P<0,05)$. Com 12 horas, $75 \%$ dos cristais da técnica 1 tinham cor rosa médio e $25 \%$ rosa fraco. Na técnica 
FRANCESQUINI Jr, L. et al. Cristais de hemoglobina em sangue de capivaras (Hydrochaeris hidrochaeris).

$2,100 \%$ dos cristais tinham cor rosa intenso e na técnica $4,64 \%$ tinham coloração rosa fraco e $36 \%$ rosa médio.

O local do cristal na lâmina também tem associação com a técnica empregada $(P<0,05)$. Assim, com 12 horas, $58 \%$ dos cristais da técnica 1 se encontravam de maneira regular e $42 \%$ irregular. Na técnica 2, 100\% se encontravam de forma regular e na técnica $4,100 \%$ de forma irregular.

As técnicas empregadas não influenciaram o contorno do cristal $(P>0,05)$.

A quantidade, o tamanho e o local do cristal não estão associados a utilização ou não do luto $(P>0,05)$.

Já a coloração do cristal foi influenciada pelo luto somente após 48 horas. Nesse intervalo de tempo, $67 \%$ dos cristais que receberam luto tinham coloração rosa intenso e $33 \%$ rosa médio, já os cristais que não receberam luto, 67\% tinham coloração rosa médio e 33\% rosa fraco.

Também só houve diferença no contorno em função do luto, no tempo de 48 horas $(P<0,05)$. Nesse tempo, $100 \%$ dos cristais que receberam luto tinham contorno regular e $100 \%$ dos que não o receberam tinham contorno irregular.

Os resultados obtidos neste estudo revelam que a técnica de Costa $^{7}$ é de grande valia, de fácil execução, mas depende de drogas de boa procedência e da manutenção das condições externas (temperatura, luminosidade, umidade, contaminação) quando do preparo e guarda das lâminas. Pois o excesso de umidade, provoca o aparecimento de fungos, já a temperatura e a umidade danificam o cristal já obtido, bem como retardam o seu aparecimento.

Concorda-se também com Dukes ${ }^{12}$, pois este afirma que em seus experimentos estes variavam amplamente quanto a cristalização, a forma e tamanho dos cristais.

A escolha dos métodos desenvolvidos por Costa $^{7}$, concorda com as escolhas de Ferreira ${ }^{14}$, Fávero ${ }^{13}$, Arbenz ${ }^{3}$.

O método para identificação de animais permite a obtenção de resultados rápidos, seguros, de baixo custo e de fácil manejo associado ao fato de dispensar pessoal, drogas, máquinas e equipamentos sofisticados e de custo elevado; a quantidade, o tamanho, a cor, o local e o contorno do cristal não estão associados ao sexo do animal e a quantidade de cristal depende da técnica empregada; a técnica 2 é a que produz mais cristais.

FRANCESQUINI Jr, L.; FRANCESQUINI, M.A.; AMBROSANO, G.M.B.; BARBOSA, C.M.R.; CORRENTE, J.E.; DARUGE, E.; SATURNINO, A.R.; CALDAS, J.C.F.G. Crystal of hemoglobin in capybaras (Hydrochaeris hidrochaeris) blood and its skillful importance. Saúde, Ética \& Justiça, 5/7(1-2):17-23, 2000-2002.

Abstract: The aim of this work was to select a method for animal identification, supplying important subsidies to characterize or not of crime as much as slaughter of wild animals as tortures of domestic ones, both protected by law, as well as verify the crystallization of the hemoglobin, precisely oxihemoglobin, in blood 'in nature' with anticoagulant and coagulate in capybaras. Preparations modified by Costa were used in this work. This technique has a low cost of implementation, it is fast to obtain results and it is easy to prepare and handle. After the compilation and data analysis, it was verified the amount, size, color, site and the contour of the crystal are not associated with the sex of animal; also, the amount of the crystal depends on the applied technique, where the technique 2 (fresh blood oxalate is spinet, the sediment is lacqued with saporin; sulfate of sodium is added and mix it up energetically during 10 minutes at speed 4) the one that yelled more crystals, bigger crystals intense coloration (pink intense) and regularly distributed in the blade.

Keywords: Rodentia. Hemoglobins. Forensic anthropology. Chrystalography/methods. Animal identification systems. 
FRANCESQUINI Jr, L. et al. Cristais de hemoglobina em sangue de capivaras (Hydrochaeris hidrochaeris).

\section{Referências}

1. Alcântara, H.R. de. Perícia médica judicial: sangue. Aparecida: Guanabara Dois, 1982. p.297-301.

2. Almeida Jr., A. Lições de medicina legal. Rio de Janeiro: Ed. Nacional de Direito, 1957. p.82-4.

3. Arbenz, G.O. Medicina legal e antropologia forense. Rio de Janeiro: Atheneu, 1988. p.75-87.

4. Brasil. Constituição da República Federativa do Brasil; Constituição 1988. Brasília: Senado Federal, 1988. 292p.

5. Brasil. Leis, decretos, etc. Lei 5.197 de 3 de janeiro de 1967. Dispõe sobre a Lei de Proteção a Fauna, Diário Oficial da União, Brasília, DF, n.4, 5 jan. 1967.

6. Brasil. Leis, decretos, etc. Lei 9.605 de 13 de fevereiro de 1998.Dispõe sobre a Lei de Proteção a Fauna, Diário Oficial da União, Brasília, DF, n.31, 13 fev. 1998.

7. Costa, C. Crystaes de hemoglobina em medicina legal. São Paulo, 1933. Tese (Doutorado) - Faculdade de Medicina da Universidade de São Paulo.

8. Costa, A.C.; Chaves, P.R. Tratado elemental de histologia y anatomia microscópica. Buenos Aires: Ed. Científico-Médica, 1953. p.260-9.

9. Daruge, E.; Massini, N.; Galdino, A.M. Ensaio de sistematização sobre o ensino de odontologia legal e deontologia odontológica. Piracicaba: FOP/ UNICAMP, 1975. p.311-9. (Apostila).
10. Di Fiori, M.S.H. Diagnóstico histológico. Rio de Janeiro: Ed. Guanabara Koogan, 1960. p.401-31.

11. Dórea, L.E.C. As manchas de sangue como indício em local de crime. Salvador: Franco Produções, 1989. p.78.

12. Dukes, H.H. Fisiologia de los animales domésticos. Madrid: Aguilar, 1962. p.33.

13. Favero, F. Medicina legal: introdução ao estudo da medicina legal, identidade, traumatologia, infortunística e tanalogia. Belo Horizonte: Itatiaia, 1980. p.183-205.

14. Ferreira, A.A. Da técnica médico-legal na investigação forense. São Paulo: Ed. Revista dos Tribunais, 1962. p.321-98.

15. Jiménez, E.G. El capibara (Hydrochoerus Hydrochaerus) estado atual de su producción. Rome: FAO, 1995.

16. Martins, S.V. Contribuição para o estudo dos crystaes de hemoglobina em medicina legal. São Paulo, 1929. Tese (Cátedra) - Faculdade de Medicina, Universidade de São Paulo.

17. São Paulo (Estado). Constituição do Estado de São Paulo; Constituição, 1989. São Paulo: Imprensa Oficial do Estado, 1989. 48p.

18. Zarzuela, J.L. Aspectos biológicos do sangue de interesse criminalístico: estudo sumário. São Paulo: Arquivos da Polícia Civil do Estado de São Paulo, 1982. p.155-9. 